\section{Assessment and sensitive analysis of biological water risks in water resources with application of classical mass transfer computations}

\author{
Farhad Mahmoudi Jalali', Mohammad Gheibi ${ }^{2 *}$, \\ Reza Aghlmand ${ }^{2}$, Amir Takhtravan ${ }^{3}$ and Zahra Kian ${ }^{4}$ \\ 1Department of Civil Engineering, Faculty of Engineering, Islamic Azad University, Tabriz Branch, Iran \\ ${ }^{2}$ Department of Civil Engineering, Faculty of Engineering, Ferdowsi University of Mashhad, Iran \\ ${ }^{3}$ Department of Civil Engineering, Birjand University of Technology, Birjand, Iran \\ ${ }^{4}$ Department of Chemical Engineering, Amirkabir University of Technology, Tehran, Iran
}

\begin{abstract}
Due to the urgent need for water in all parts of industrial or developing societies, water supply, and transmission facilities are suitable targets for biological risks. Given that even a short interruption in water supply and water supply operations has a great impact on daily activities in the community, the deliberate contamination of urban water resources has irreparable consequences in the field of public health, and the economy of society will follow. Unfortunately, most officials in the public health control departments in our country have received limited training in detecting accidental or intentional contamination of water resources and dealing with the spread of waterborne diseases both naturally and intentionally. For this reason, there is low preparedness in the responsible agencies to deal with waterborne diseases during biological risks. In the first step of this research, a review study has been conducted on water biological risks and operational strategies to deal with them. In the following, it has studied how Escherichia coli ( $E$. coli) bacteria spread in aqueous media. In this regard, the kinetic model of the studied microorganism was analyzed based on the implementation of (Fick Law) in polar coordinates and the combination of (Dirac Distribution) with (Legendre polynomial) distribution. Finally, after studying the factors affecting the microbial pollutant emission coefficient, the effects of all three factors of linear velocity, linear motion time period, and angle of motion on the pollutant emission flux and biofilm diffusion time in the water supply network environment were investigated. Studies have shown that the linear velocity parameter of Escherichia coli with a nonlinear relationship has the greatest effects on the release of microbial contaminants.
\end{abstract}

\section{More Information}

*Address for Correspondence: Mohammad Gheibi, Department of Civil Engineering, Faculty of Engineering, Ferdowsi University of Mashhad, Iran, Email: Mohammadgheibi@ymail.com

Submitted: May 17, 2021

Approved: June 07, 2021

Published: June 09, 2021

How to cite this article: Jalali FM, Gheibi M, Aghlmand R, Takhtravan A, Kian Z. Assessment and sensitive analysis of biological water risks in water resources with application of classical mass transfer computations. Ann Biomed Sci Eng. 2021; 5: 015-024

\section{DOI: 10.29328/journal.abse.1001013}

Copyright: ( 2021 Jalali FM, et al. This is an open access article distributed under the Creative Commons Attribution License, which permits unrestricted use, distribution, and reproduction in any medium, provided the original work is properly cited.

Keywords: Biological risks; Water resources; Escherichia coli; Fick's law; Microbial penetration

\section{(D) Check for updates}

( OPEn Access

\section{Introduction}

Biological risks in different parts of the world have increased the risk of contamination of water resources and water supply facilities. Water plays a very important role in every part of society. Thus, water resources and transmission networks become potential targets for biological hazards. Even a short interruption in water supply and transmission operations will cause irreparable social, economic, and political damage. In the past, protecting water from hazards was limited to the military and military forces, as maintaining the health of soldiers on the battlefield and difficult conditions against waterborne diseases were important priorities [1-3]. A study of some of the events of the last few decades that have caused the outbreak of waterborne diseases and the loss of life and property can show the importance of preventive measures against chemical and biological risks on water resources and facilities. For example, the outbreak of Cryptosporidiosis in Milwaukee, Wisconsin in 1993, killed 54 people, infected more than 400,000 with diarrhea, and hospitalized more than 4,000 of the city's population. It is estimated that the accident caused \$54 million in damage to the city's economy, 
resulting in the loss of 725,000 working days. Also in 2000, $E$. coli 0157: H7 infected 7 water sources in Walkerton, Ontario, Canada, killing 7 people and infecting 2,300 city dwellers [4-7]. The reconstruction of the network and the installation of water disinfection equipment were estimated to cost \$11 million. Damage from the accident is currently estimated at $\$$ 155 million. Biological risks that target water resources and facilities, both covertly and openly through biological and chemical agents, threaten public health infrastructure. Many experts consider the possibility of using biological weapons to target water resources and networks very high, so it is necessary to prepare all responsible institutions against the possible occurrence of these hazards [8-12].

\section{Water pollution and public health challenges}

Although public health professionals cannot prevent the onset of the first symptoms of the disease or poisoning due to the spread of biological agents, they still play a very important role in reducing the impact of these risks in the communities covered [13]. Despite the low probability of a biological risk on water resources, the consequences and damage from these hazards which affect public health will be very serious. Prompt and timely diagnosis and crisis management, including preventive measures, preparedness of relief professionals, and relief equipment, are among the factors that lead to an appropriate response in times of crisis and prevent chaos in society. Therefore, rapid and timely detection of biological risks on water infrastructure is essential to properly respond to these risks [6]. In a scenario of a biological risk on water resources and facilities, early and rapid detection is necessary to reduce the impact of pollution on public health, reduce the negative psychological impact on public opinion, and prevent further problems in water supply and distribution [8]. Recognizing and managing the signs of water pollution in the best conditions is also a major challenge for water supply network officials. Some of the public health challenges associated with waterborne risks related diseases are listed below [14-19].

1 - Rapid detection of waterborne diseases may be difficult at first. Many diseases that are spread through the use of biological risks are usually difficult to diagnose in the early stages of the disease, and in some cases, they are not much different than another common disease that usually affects people. In addition, the signs and symptoms of waterborne disease are often vague and more like other medical conditions and disorders that have little to do with waterborne diseases.

2 - Many biological agents show completely different clinical signs when consumed. If epidemiological research and clinical evaluations are limited to examining the ways in which a biological agent enters the body, it can confuse diagnosis, delay treatment, and prevent public health safeguards.

3 - The occurrence of diseases on water resources in communities and small towns can be a warning sign for future hazards. To reduce the likelihood of such hazards, sampling of water sources and monitoring of health center statistics should be done regularly, even in villages and small towns.

4 - Public health professionals play a key role in diagnosing waterborne diseases and are at the forefront of combating the destructive effects of these risks. Although water sampling methods and laboratory devices for detecting intentional contamination of water have made great strides and are constantly improving, one of the first signs of an outbreak of biological risk is an increase in patient visits at health centers. Rapid identification, accurate diagnosis, testing as soon as possible, and the preparation of comprehensive reports are important steps in preparing for biological risks.

5 - Waterborne diseases, which are caused by the use of biological agents, may present as benign or very limited symptoms in some patients, while in others they may cause death. The impact of a biological risk depends not only on the type of biological agent used but also on the type of target community and their natural physical resistance. Individual resistance to certain biological compounds, such as aquatic agents, varies widely among the target population, making the diagnosis relatively difficult.

6 - An effective and coordinated response to a biological risk on water resources depends on the cooperation of a regular group of relevant experts. As can be seen in any biological risk scenario, a coordinated and effective response to reduce the negative consequences of pollution depends on the cooperation of public health professionals, health and water experts, law enforcement officials, and political officials.

7 - When a biological risk occurs, public health professionals are required to communicate quickly and effectively with the public and raise awareness. Physicians and health professionals play a key role in controlling emotional reactions during these hazards because they are trusted by people for the accuracy of health information related to water health.

Establishing effective communication between the medical community and the health sector in a community in times of crisis plays a key role in coordinating responses to biological risk on water resources. It is essential to prevent panic and chaos in a society that has been the target of such risks. This becomes a major challenge when there is a lot of pressure from the public and the media to provide information before credible results are obtained. Proper management of such communications and the immediate provision of essential information about the current situation is as important as the provision of medical services in the event of a biological risk [20-22]. The appropriate response to public health threats should include proper training and preparedness in the event of biological risk. Among the basic measures in preparing the medical community and public health professionals against such hazards include strengthening the ability of individuals to correctly diagnose, treat and care for the ability to manage 
public panic arising from the impact of biological risks. In addition, health professionals need to be familiar with how to communicate effectively with law enforcement, water supply, and distribution officials, and, of course, the public. If there is an appropriate response from the medical community and health professionals to a biological risk on water resources, it is essential to have a full understanding of waterborne diseases and how to properly manage patients and the treatment process [23-25]. Dealing with diseases caused by biological risk goes through a different procedure than usual treatment procedures. Most physicians and nurses have received very limited training in how to respond appropriately to biological risks. Therefore, the level of preparedness among public health authorities in the face of these hazards is very low [26].

\section{Water as a diffuser in bio-attacks}

Historically, contaminating wells, reservoirs, and water resources in urban communities have been used as a military strategy during wars. Many military forces and armies have used biological weapons to advance their goals in warfare and inflict maximum casualties on opposing forces [27]. For example, during the war, the Romans contaminated the drinking water sources of the enemies by using the corpses and carcasses of animals, and in a way pioneered the use of biological weapons in wars. With the advancement of science and technology, the mechanism of expansion and the effects of these weapons have also undergone many changes. In addition, bio-attacks, which are associated with the release of certain biological agents, are difficult to detect in a short time. The use of pathogens and biological toxins that are colorless, tasteless, odorless, and therefore indistinguishable from the human senses has become a major challenge for environmentalists. Unfortunately, little effort has been made in the various institutions responsible for upgrading equipment and devices for detecting compounds in water [28-30]. As a result, water facilities are now more physically protected by advanced equipment and are very vulnerable to the release of certain pollutants into the network (Table 1) [31-34].

\section{Dissemination of biological weapons through various means, including water}

Possible scenarios related to water pollution: The nature and extent of medical and public health effects caused by deliberate pollution of water resources depend on several factors, including [35-37]:

\section{1 - The way the biological agent spreads}

2 - Biological agent characteristics including toxicity and contagion

3 - The amount of biological agent released in nature and the amount of its contagious dose

4 - Physical condition and health of people exposed to biological agents and their immune system's ability to Figureht disease

\section{5 - Ways of releasing a biological agent}

\section{6 - How biological agents are distributed in nature}

One of the challenges for physicians and paramedics during biological risks is to identify the type of biological agent from its signs and symptoms. In most cases, patients do not have a proper understanding of the disease and the signs of the spread of biological agents, thus reducing the ability to diagnose the disease and its cause by physicians and medical professionals. For this reason, medical officials must be in full contact with disease control specialists in specialized centers for the study of biological agents in order to have a full understanding of the signs and side effects of biological weapons and be prepared to face potential threats. Some of the scenarios that may be related to the detection of the spread of biological agents related to the biological risk that causes the spread of the disease in society are discussed below [38-40].

1 - Deliberate contamination of water resources may be caused by biological agents not produced for military use. In most cases, diseases caused by the use of the biological risk of biological weapons have similar symptoms to common diseases because the causative agent is also found naturally in nature. Diseases that occur naturally in water due to the spread of contamination can be just as deadly and dangerous. For this reason, water pollution by pathogens that are commonly found in nature must be considered. Reference to the history of outbreaks of waterborne diseases in the community and their symptoms can be useful in this regard.

Table 1: High access points during biological risks. Biological risk points

Description

\begin{tabular}{|c|c|c|}
\hline $\begin{array}{c}\text { Biological risk points } \\
\text { Upstream areas of reservoirs and water collection } \\
\text { areas }\end{array}$ & Water supply facilities are composed of water bodies such as dams, rivers, wells, service tanks, etc. with the low- \\
intensity flow that can be used as points to contaminate water.
\end{tabular}


2 - If the paths of absorption of diseases are diverse, it can cause different symptoms. For example, symptoms of illness when the agent is absorbed through the digestive, it will be very different from when absorbed through skin or breathing. The release of pollution through food consumption can affect the accuracy of the results of medical examinations. Many of the biological pathogens in the event of absorption of the digestive, are quite different symptoms than when absorbed by breathing or skin.

3 - In the case of using various biological factors in a biological risk, the probability of occurrence of instantaneous symptoms in patients can be present. The simultaneous release of different biological factors will lead to symptoms of various diseases, and as a result, the process of diagnosis and treatment is difficult. As a result, the possibility of using several different biological factors should be considered.

4 - Water can act as a transmitter factor of pollution from the main source and secure sources of pollution in nature. Toxic agents in biological weapons, if used in various types of water resources such as lakes, water parks, rivers, and water tanks, water and surroundings directly infect. However, pollution can also be done indirectly. For example, if the runoff from the region that has been proposed by biological risks and poisonous biological agents, will enter rivers, lakes, and other water resources, causing pollution of these areas. Perhaps medical procedures based on disinfection of the patient using solutions with blue base solutions produce toxic sewage, which is capable of infecting other water resources.

Publish toxic biological agents from different ways: Biological weapons may be used by unusual means by unusual mechanisms and release pathogens. Biological toxic agents are published in many ways. This publication can be carried out through food pollution or livestock and poultry, or through direct pollution of the resources of the target community. These ways include emissions through air and absorption through lashes, transmission through food and water, absorption through skin contact, and direct injection. Biological factors may absorb the body in common, such as other pathogens, such as viruses or bacteria. The proper readiness of the medical community against biological risks should include information on the entry of pathogenic factors to the body to prevent further dissemination of disease in the community and the occurrence of epidemics. There are many challenges against health professionals during the occurrence of biological risk. One of the key factors for raising the accuracy of detection and efficient management of the crisis is considering water as the transmission of pathogens and biological toxins. The factors used in biological weapons are often published in many ways, including water. In table 2 , a number of biological factors known by governments, military forces, and disease control centers are known as dangerous and publishing factors in various ways [41-43].

Diagnosis of diseases caused by the release of pathogens in water resources: From the perspective of theory, any pathogens and pathogens can be used as biological weapons in biological risks, but in practice, the number of microbial and pathogenic factors used in the dominant biological weapon is very limited. However, the list of these factors is continuously transformed because their number and nature are changing, which creates new challenges for doctors [44,45]. General health professionals face many challenges when faced with

Table 2: List of some biological factors and toxins threatening human health [46-50].

\begin{tabular}{|c|c|c|}
\hline \multicolumn{3}{|c|}{ Pathogens } \\
\hline Etiological factor & Source & Ways of transmission \\
\hline Anthrax & Soil & Air, food, contact with contaminated tissue \\
\hline Brucellosis & Cattle, pigs, goats, sheep, camels, dogs, jackals & Air, food, superficial contact with mucus \\
\hline Cholera & Aquatic environment & Food, water, wound washing with contaminated water \\
\hline Melioidosis & water and soil & $\begin{array}{c}\text { Contact with contaminated water and soil, inhalation of } \\
\text { steam or contaminated water, inhalation of contaminated } \\
\text { dust }\end{array}$ \\
\hline Plague & Domestic and wild animals, rabbits & Air, widespread \\
\hline \multicolumn{3}{|c|}{ Parasitic pathogen } \\
\hline Etiological factor & Source & Ways of transmission \\
\hline Cryptosporidiosis & $\begin{array}{l}\text { Humans, a wide range of animals such as cattle and } \\
\text { other domestic animals }\end{array}$ & Food, water, human to human, animal to human, air \\
\hline \multicolumn{3}{|c|}{ viruses } \\
\hline Etiological factor & Source & Ways of transmission \\
\hline Hepatitis A. & Humans, primates & Man to man, water, food \\
\hline \multicolumn{3}{|c|}{ Plant-based toxins } \\
\hline Etiological factor & Source & Ways of transmission \\
\hline Ricin & Ricinus Communis & Inhalation of polluted air in industrial processes, food \\
\hline \multicolumn{3}{|c|}{ Bacterial-based toxins } \\
\hline Etiological factor & Source & Ways of transmission \\
\hline $\begin{array}{l}\text { Clostridium botulinum } \\
\text { toxins }\end{array}$ & Soil, animals, fish & $\begin{array}{l}\text { Foods contaminated with botulinum toxin } \mathrm{C} \text {, wound } \\
\text { infection caused by exposure to toxin spores }\end{array}$ \\
\hline $\begin{array}{l}\text { Clostridium perfringens } \\
\text { toxins }\end{array}$ & $\begin{array}{l}\text { Soil and gastrointestinal tract of healthy humans and } \\
\text { animals }\end{array}$ & $\begin{array}{l}\text { Food wound infection caused by exposure to toxin } \\
\text { spores }\end{array}$ \\
\hline
\end{tabular}


these diseases and their treatment. Although the highest impact of these pathogens is released in a gas, the release of these factors in food and water is also as dangerous. The biological causes of pathogens, which are capable of biological weapons, include a variety of bacteria, viruses, and many other microorganisms.

Diagnosis of diseases caused by the release of biological toxins in water sources: Biological pesticides can also be used as biological weapons due to their high toxicity and rapid and easy release. Biological toxins are one of the most important and complex groups that can be used in biological weapons. These toxins are extracted from the biological activities of bacteria, fungi, some plants, and algae or marine species. These natural toxins are considered to be the most toxic compounds known to man, very small amounts of these compounds (in nanograms) are very lethal. In general, many of the biological toxins used in military weapons are used for diffusion into the air and absorption through respiration [51]. However, many of these toxins have the potential to release into the aquatic environment and contaminate drinking water sources under the right conditions. Many of these toxins are dangerous to public health and are stable in water and cannot be detected and tracked by conventional devices and methods. Some of these toxins that can be used in military weapons include bacterial toxins, micro toxins, toxins derived from fungi, plants, and algae, and marine toxins. Many of these toxins are perfectly stable under normal conditions in water and have very serious side effects if they come in contact with, absorb or digest in the body [52]. Biological toxins have a wide range of physical and biological properties and have the ability to act in different ways that cause a wide range of diseases in humans. Many of these toxins contain compounds such as aflatoxins, botulinum, and raisin. They are currently used in biological weapons and there is a possibility of military use of other biological toxins such as Microcystin, Saxitoxin, T-2 Mycrotoxin, Staphylococcal enterotoxin, and Tetrodotoxin. There is evidence that sufficient amounts of Microcystin, which are naturally produced in ponds and stagnant water, can be used in biological weapons. Biological toxins are complex chemical compounds that have a wide range of water solubility, reactivity, and degradability in the environment. In addition, a specific compound such as botulinum can have varying degrees of stability and toxicity in the aqueous medium between types A, B, C, D, and E [53-55].

Use of diagnostic indicators and epidemiological models to diagnose the use of biological agents and waterborne diseases: Although certain diagnostic methods for detecting intentional contamination of water networks are evolving rapidly, the most reliable way to determine water resource pollution is to consider changes in the incidence of various diseases. Thus, the first signs of a biological risk can be an increase in the number of patients in the emergency department of hospitals or the spread of unusual diseases. Humans are generally the most sensitive and the only detector in many cases of biological agent release [56]. Consequently, health officials and physicians should be aware of their prominent role in countering the spread of biological pathogens and in the event of biological risks, inform and provide solutions. The symptoms of waterborne diseases due to the use of biological agents may be very similar to other endemic diseases. However, these signs can indicate the occurrence of biological risk. Numerous published epidemiological patterns and hospital information serve as a valuable resource for physicians and public health professionals when faced with the challenge of diagnosing biological diseases. These epidemiological indicators may be the result of various routes of disease transmission, such as contaminated water consumption, and have international applications in public health [57-59].

Use disease monitoring and progression to help diagnose biological risks on water resources: Although laboratory tests for diagnostics, general health monitoring, and accurate disease reporting have increased, these methods alone are not able to detect the prevalence of diseases caused by biological risks. One way to improve these methods is to use symptom monitoring, which uses the diagnosis of signs and symptoms of a large group of patients in the hospital emergency room. Acceptance of the use of disease monitoring as a diagnostic tool will be very effective in the early detection of suspected cases of waterborne diseases associated with biological risks [60]. The advantage of using this approach to diagnose waterborne diseases in the event of a biological risk is based on monitoring the signs of the disease process by grouping cases. Many local and national organizations are developing and implementing a symptom monitoring system to complement older methods of diagnosing the disease. For the medical community, due to the ability to quickly diagnose acute categories of disease caused by biological risks, the symptom monitoring system may need to increase the emergency space. Public health professionals should pay close attention to the possibility of misdiagnosis of the following symptoms in patients, which could indicate the use of biological agents in water $[61,62]$.

- Diarrhea and vomiting due to poisoning by overt general pathology or direct contact with biological toxins

- Respiratory diseases associated with fever and sudden death from myocardial infarction

- The simultaneous appearance of sores, purulent blisters, and fever

- Meningitis, encephalitis, and encephalopathy in suspected cases

- Infectious poisoning or shock

- Death from a history of fever 
- Advanced cranial neuropathy with progressive general weakness

None of these diseases alone indicate the occurrence of biological risk, but they can indicate the course of the disease, which in itself is a reason for the need for further research.

\section{E. coli rotational diffusion model in aqueous media}

Based on a kinetic structure called Flagellar, E. coli transform rotational motion into a linear motion and propagates in aqueous media at a linear velocity of up to $20 \mu \mathrm{m} / \mathrm{s}$. The general structure of this locomotor system is shown in figure 1 [63].

Research shows; This microorganism has an average time period of 0.1 seconds for rotational motion and 1 second for linear motion. After completing a complete movement cycle consisting of a series of rotational movements and in a linear path, it redirects and continues the path. These linear routines are not completely random and have a systematic criterion based on Brownian Motion Which is shown based on Equation 1 [64].

Equation 1

$$
\begin{aligned}
& \mathrm{D}_{t}=\mathrm{V}_{\text {run }}^{2} \times \tau_{\text {run }} \\
& \tau_{\text {run }} \rightarrow \text { average duration of each run } \\
& \mathrm{V}_{\text {run }} \rightarrow \text { velocity the bacterium in a straight line } \\
& \mathrm{D}_{t} \rightarrow \text { diffusivity coefficient }
\end{aligned}
$$

The motion of the microorganism is usually expressed as a probability density function depending on the polar angle, horizontal angle, and time. The Brownian path and randommicroorganism are shown in figure 2 [65].

In order to determine the rotational motion and to examine the possible functions to evaluate the randomness of E.coli motion, the relation of Fick's law is analyzed, in which $D_{r}$ is the rotational diffusion coefficient and $\rho$ also expresses the probability density. The Dirac Delta distribution was also used to expand and simplify the Fick model as per Equation 2 [66].

Equation 2

$$
\begin{aligned}
& \frac{\partial \rho}{\partial t}=\mathrm{D}_{r} \Delta \rho \\
& \mathrm{D}_{r} \rightarrow \frac{\operatorname{rad}^{2}}{s} \\
& \rho(\theta, t)=\sum_{l=0}^{\infty} \frac{2 l+1}{2} \mathrm{e}^{-D_{r} l(l+1) t} p_{l} \cos \theta \sin \theta
\end{aligned}
$$

In the above relation, $\mathrm{P}_{\mathrm{L}}$ expresses the order of polynomial distribution of the ligand with $\mathrm{L}$ index. How to distribute the above function for different times and in the range [0 - 2Pi] is shown in figure 3 [67].

Analysis of the mentioned Figure. shows that if the value of movement time is $t \leq \frac{1}{2 D_{r}}$, the microorganism does not have random motion and is based on memory because the value of the density function is a high probability and its motion is selective. Whereas if it is $t \geq \frac{1}{2 D_{r}}$, the value of the density

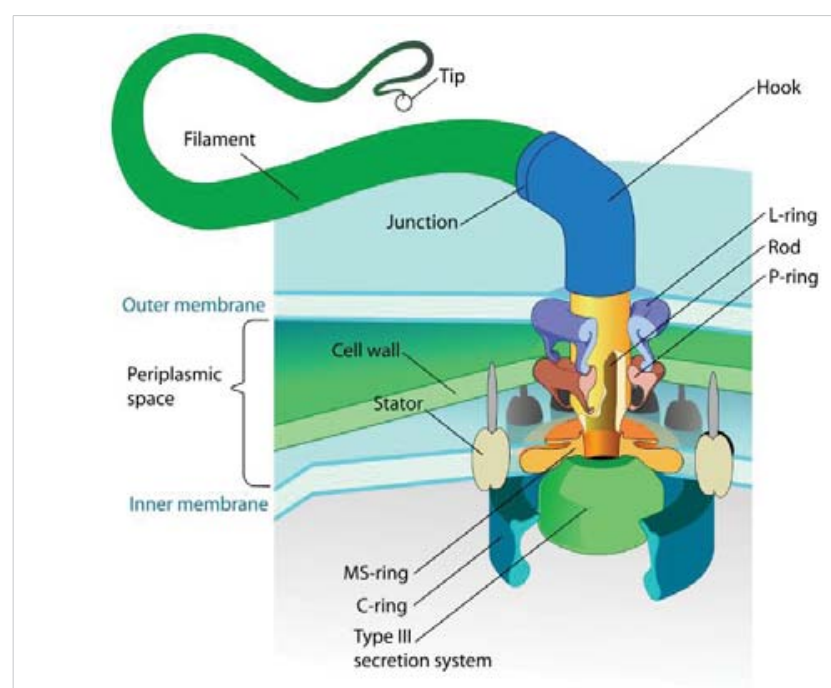

Figure 1: Components of the motor organs of $E$. coli in rotational and linear pathways.

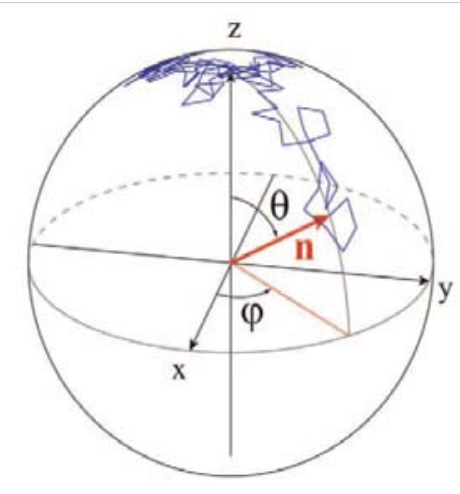

Figure 2: Random path and possible E. coli microorganisms in spatial coordinates.

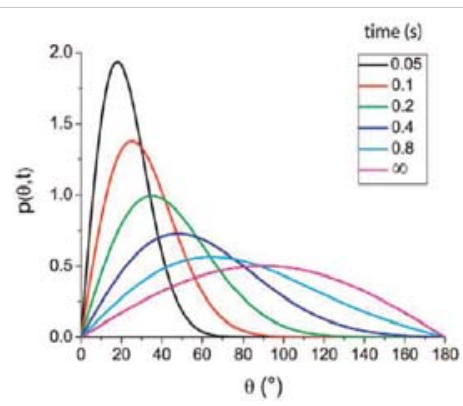

Figure 3: Changes in the probability density function in the rotational motion of E. coli microorganisms. 
function of probability is reduced and the movement of the microorganism is based on a random path. This is the case when the infinite equivalent time is $\rho(\theta, t \rightarrow \infty)=\frac{1}{2} \sin \theta$, and in the extreme case, the value of the probability density function is 0.5. Various Equations have been proposed to determine the amount of $E$. Coli penetration coefficient in aqueous media. This study uses the Equation proposed by Lovely and Dahlquist (Equation 3) [68-69].

Equation 3

$$
D_{t}=\frac{1}{3}\left[\frac{V_{r u n}^{2} \tau_{r u n}}{1-\cos \theta}\right]
$$

\section{Evaluation of microbial contamination transmission flux and the effects of effective parameters on the diffusion coefficient}

In this part of the study, a microbial contamination scenario is plotted and then examined using mathematical models. In this scenario, it is assumed that the microbial agent is emitted from a $5 \mathrm{~mm}$ thick biofilm plate containing Escherichia coli into the municipal water network. It is very clear that in the urban water network, diffusion and mass flow mechanisms (Advection) emit pollution simultaneously and in parallel. Therefore, Equation 4 is used to calculate the flux values, mass transfer rate, and propagation time [70].

Equation 4

$N_{A Z}=\alpha \frac{D_{t} C}{Z} \operatorname{Ln} \frac{\alpha}{\alpha-x_{A i}}$

$\alpha=\frac{N_{A Z}}{N_{A Z}+N_{B Z}}, \mathrm{~A} \rightarrow$ E.Coli and $\mathrm{B} \rightarrow \mathrm{H}_{2} \mathrm{O}$

$m_{-} d o t=N_{A Z} M_{A}+N_{B Z} M_{B}$

Time $=\frac{\rho h}{2\left(m_{-} d o t\right)}$

$p_{\text {E.Coli }}=1.105 \frac{\mathrm{gr}}{\mathrm{ml}}, \alpha=0.2, \mathrm{Z}=0.03 \mathrm{~mm}, \mathrm{~h}=5 \mathrm{~mm}, \mathrm{x}_{A i}=0.2, \mathrm{C}=50 \frac{\mathrm{mg}}{\text { litr }}$

Next, the above mass transfer relationships are implemented in the Excel 2016 program environment and with changes of three-speed parameters (V) in the range of 3-25 micrometers per second, the polar angle (Teta) in the range of 30 to 85 degrees, and time in the interval of 1 to 3.2 seconds, the effect and trend of time tolerances required for full propagation and diffusion flux were evaluated.

The results of changes in E. coli emission flux relative to linear velocity, time of each movement period, and angle of motion are shown in figures 4-6.

As seen in the declared Figure., the velocity parameter has a non-linear direct relationship with the flux of microbial contaminantrelease in the water supply network environment. On the other hand, due to the second-order of this factor in terms of penetration coefficient, slope, and, consequently,

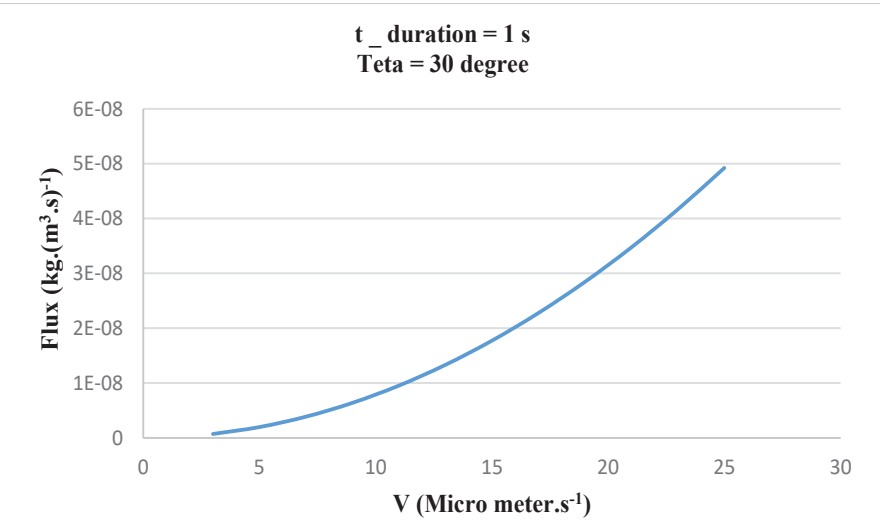

Figure 4: Changes of Flux E. coli emission relative to the linear velocity in the proposed scenario.

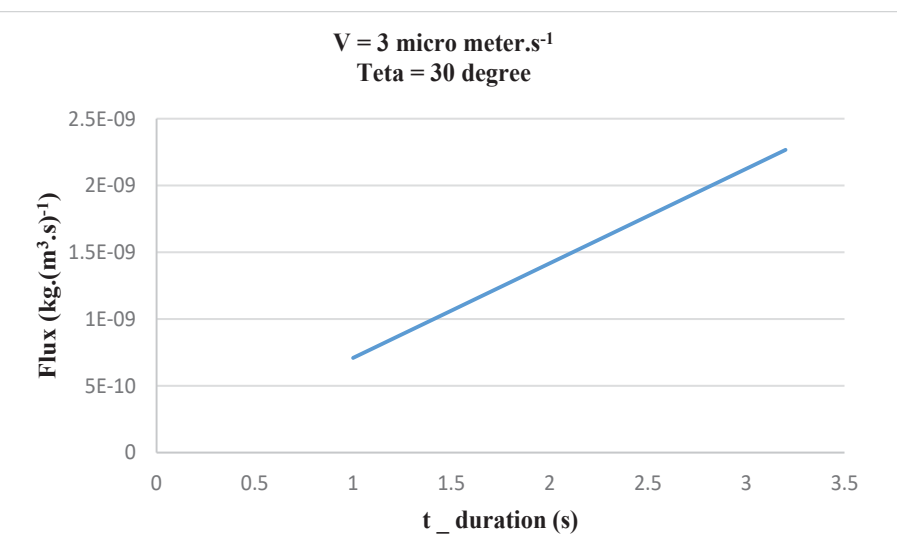

Figure 5: Changes of Flux E. coli emission relative to the Linear motion period in the proposed scenario.

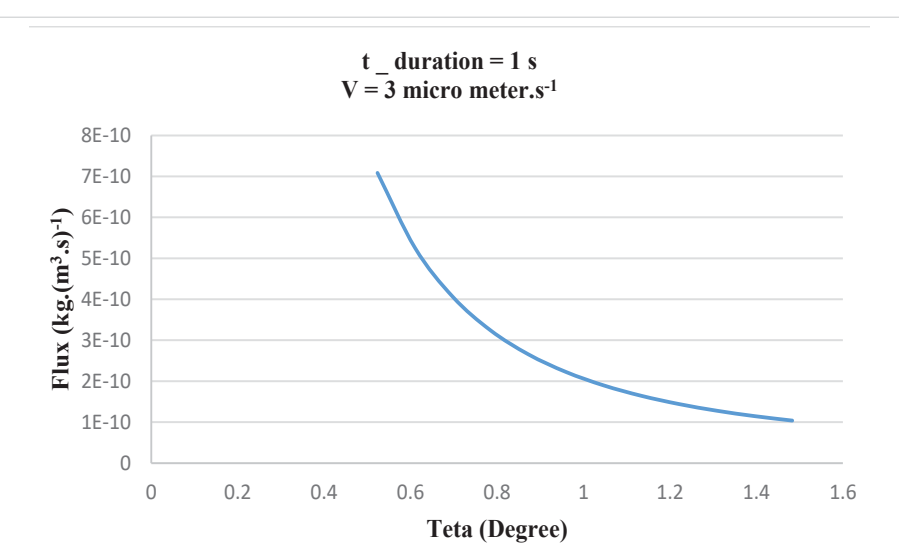

Figure 6: Changes of Flux E. coli emission relative to the angle of motion in the proposed scenario

the effect of this parameter on the amount of pollution flux is more than the other two parameters. According to figures 5 and 6, it is clear that the time period of motion has a direct linear relationship and the angle of motion also has an inverse nonlinear relationship. Also, due to the cosine shape and the range of numerical changes, the angle of motion factor has a greater effect on the emission flux than the parameter of time periods of motion. The results of changes in the release time of the full release biofilm flux containing E. coli relative to the linear velocity, time of each movement period, and angle of motion are shown in figures 7-9. 
As seen in the mentioned Figures, the velocity parameter has a very large slope and plays the greatest effects (nonlinear inverse) at the time of pollutant emission. Also, two parameters of the time period of linear motion (inverted nonlinear) and angle of motion (straight nonlinear) with the same rate are effective on the pollutant emission time. The purpose of investigating the behavior of microorganisms on how microbial contaminants are released is to determine the effective contamination time in water supply networks. In other words, it is determined, in case of intentional contamination with the mentioned conditions, how long and

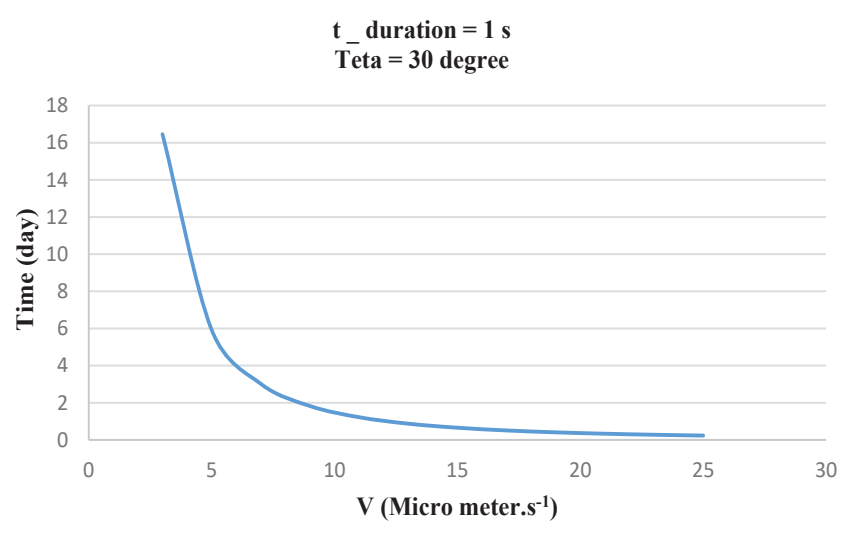

Figure 7: Changes in the full release time of the biofilm relative to the linear velocity in the proposed scenario.

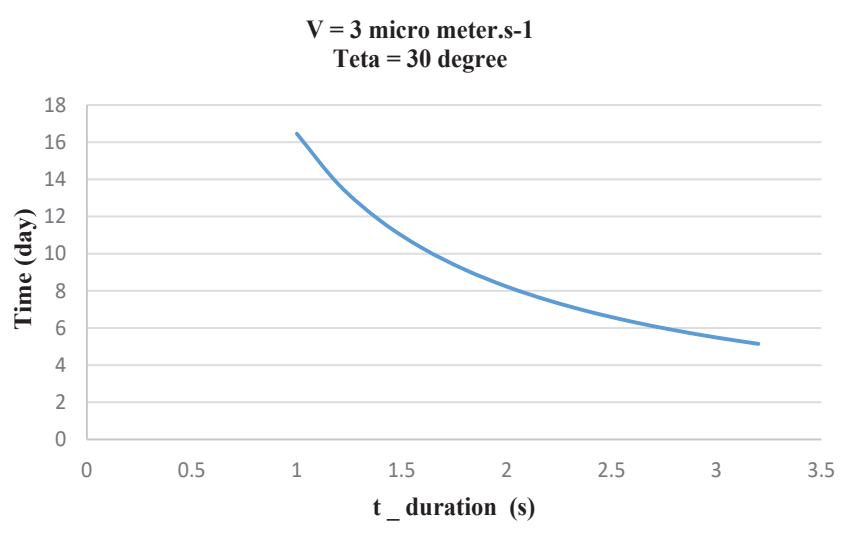

Figure 8: Changes in the complete release time of the biofilm relative to the linear motion period in the proposed scenario.

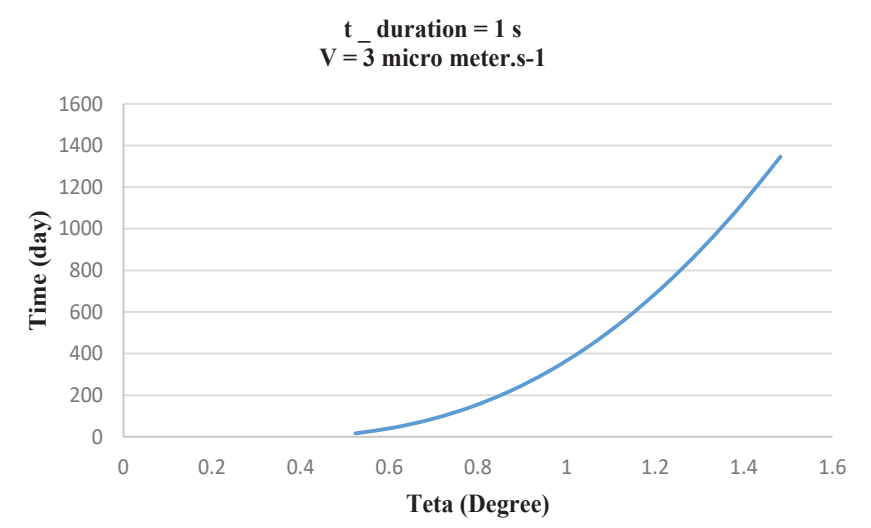

Figure 9: Changes in the full release time of the biofilm relative to the angle of motion in the proposed scenario. with what intensity the release will take place. Yi Hang, et al. in 2019 have developed an integrated urban catchment-pipeslake modeling approach to simulate the impacts of $E$. coli from stormwater sewer flows on recreational water quality. The results show that $E$. coli concentration remains at a very high level during $3 \mathrm{~h}$ after rains, while it takes about 24 hours to return to a good water quality level. therefore, lakes, streams, and all water resources which is exposed to rain should be considered as an important source with high potential for biological risks [71].

\section{Conclusion}

One of the most important issues in water resources management and management of water supply networks is to pay attention to insecurities and biological risks. One of these hazards is the biological risk which various aspects of realization and operational strategies to deal with it are mentioned in this study. Also, in the continuation of the research, the locomotor and translational structure of Escherichia coli was examined, evaluated, and introduced. The Equations of rotational motion were analyzed according to Fick's law and analyzed using the Dirac Delta distribution and the Leander polynomial distribution. Mathematical studies of the curves showed that Escherichia coli performs orientation and rotational motion based on memory in short intervals. While in longer periods, it has a completely random and random movement. This result was achieved based on the study of the behavior of the time-angle probability density function. At the end of the study, the effects of linear velocity parameters, time of each movement period, and angle of movement of microorganisms on the emission flux and the time of the complete release of biofilm in the environment were estimated. The results showed that linear velocity with a non-linear and direct relationship on flux has the greatest effects on pollutant emissions.

\section{References}

1. Da Re S, Le Quéré B, Ghigo JM, Beloin C. Tight modulation of Escherichia coli bacterial biofilm formation through controlled expression of adhesion factors. Appl Environ Microbiol. 2007; 73: 3391-3403. PubMed: https://pubmed.ncbi.nlm.nih.gov/17384304/

2. Brenner MP, Levitov LS, Budrene EO. Physical mechanisms for chemotactic pattern formation by bacteria. Biophys J. 1998; 74: 1677-1693. PubMed: https://pubmed.ncbi.nlm.nih.gov/9545032/

3. Perrin F. Mouvement Brownien d'un ellipsoide (II). Rotation libre et dépolarisation des fluorescences. Translation et diffusion de molécules ellipsoidales. J de Physique et Le Radium. 1936; 7: 1-11.

4. Perrin F, Bruhat G, Weil L, Bauer E, Bernamont J, et al. Brownian motion of an ellipsoid. II. Free rotation and depolarisation of fluorescence: translation and diffusion of ellipsoidal molecules. J de Physique et Le Radium. 1936; 7.

5. Hrudey SE, Hrudey EJ, Pollard SJ. Risk management for assuring safe drinking water. Environ Int. 2006; 3 2: 948-957. PubMed: https://pubmed.ncbi.nlm.nih.gov/16839605/

6. Liu L, Qu Y, Huang J, Weber R. Per-and polyfluoroalkyl substances (PFASs) in Chinese drinking water: risk assessment and geographical distribution. Environ Sci Eur. 2021; 33. 
7. Almeida MD, Carriço N, Santos J, Eslamian S. Risk Analysis of Water Harvesting Systems. In: Handbook of Water Harvesting and Conservation: Basic Concepts Fundament. 2021: 177-189.

8. Wade M, O'Brien GC, Wepener V, Jewitt G. Risk assessment of water quantity and quality stressors to balance the use and protection of vulnerable water resources. Integr Environ Assess Manag. 2021; 17: 110-130.

PubMed: https://pubmed.ncbi.nlm.nih.gov/33058386/

9. Yang B, Yang H, Zhang C, Wang Y. Risk Assessment and Countermeasures of Heavy Metals in Drinking Water Environment of Guizhou Province. InE3S Web of Conferences. EDP Sciences. 2021; 245: 02012.

10. Wuijts S, Van Rijswick HF, Driessen PP. Achieving European Water Quality Ambitions: Governance Conditions for More Effective Approaches at the Local-Regional Scale. Sustainability. 2021; 13: 681.

11. Sun Y, Ahmad M, Rui L, Ahmad S, Khan YA. Aspiration of PublicPrivate Partnership Projects' Risk Management Supported on Probabilistic Linguistic Terms amid Weakened Hedges. Mathematical Problems in Engineering. 2021; 1-17.

12. Chen X, Li F, Zhang J, Liu S, Ou C, et al. Status, fuzzy integrated risk assessment, and hierarchical risk management of soil heavy metals across China: A systematic review. Science of The Total Environment 2021; 785: 147180.

13. Barilari A, Calderon G, Massone HE. Risk Management of Groundwater Pollution, Sustainability and Quality of Life: The Gap Between Theory and Practice in an Intermediate City of the Global South (Mar Del Plata, Argentina). In: Handbook of Quality of Life and Sustainability. 2021; 317-335

14. Asante-Duah DK. Hazardous waste risk assessment. CRC Press; 2021.

15. Pelekanos N, Nikolopoulos D, Makropoulos C. Simulation and vulnerability assessment of water distribution networks under deliberate contamination attacks. Urban Water J. 2021; 7: 1-4.

16. Alguliyev R, Imamverdiyev Y, Sukhostat L. Hybrid DeepGCL model for cyber-attacks detection on cyber-physical systems. Neural Computing and Applications. 2021; 7 : 1-6.

17. Singh M, Kaptchuk TJ, Henrich J. Small gods, rituals, and cooperation: The Mentawai water spirit Sikameinan. Evolution and Human Behavior. 2021; 42: 61-72.

18. Hotez PJ. Anti-science kills: From Soviet embrace of pseudoscience to accelerated attacks on US biomedicine. PLoS Biol. 2021; 19: e3001068. PubMed: https://pubmed.ncbi.nlm.nih.gov/33507935/

19. Tuptuk N, Hazell P, Watson J, Hailes S. A Systematic Review of the State of Cyber-Security in Water Systems. Water. 2021; 13: 81.

20. Lee C, Chae YH, Seong PH. Development of a method for estimating security state: Supporting integrated response to cyber-attacks in NPPs. Ann Nuclear Energy. 2021; 158: 108287.

21. Alshehri M, Bhardwaj A, Kumar M, Mishra S, Gyani J. Cloud and IoT based smart architecture for desalination water treatment. Environ Res. 2021; 195: 110812.

22. Bross L, Krause S. Will There Be Enough Water? A System Dynamics Model to Investigate the Effective Use of Limited Resources for Emergency Water Supply. Systems. 2021; 9: 2.

23. Karaki BJ, Mahmoud MS. Scaled consensus design for multiagent systems under DoS attacks and communication-delays. J Franklin Instit. 2021; 358: 3901-3918.

24. Dinsdale G, Manning J, Herrick A, Dickinson M, Taylor C. O15 Using a smartphone app to characterise and quantify skin colour changes in Raynaud's attacks. Rheumatology. 2021; 60.

25. Dai K, Zhang N, Zhang L, Yin L, Zhao Y, et al. Self-supported Co/CoO anchored on $\mathrm{N}$-doped carbon composite as bifunctional electrocatalyst for efficient overall water splitting. Chem Eng J. 2021; 414: 128804.

26. Marinova I, Marinov M, Romanova H, Stavrev D. Marine and waterrelated bio-incidents and preparedness for bioterrorism and biothreats. In Varna Medical Forum. 2021; 10.

27. Elyasa Y. Bioterrorism: the development and its regulations according to the international law. Lampung J Int Law. 2021; 3: 29-40.

28. Theodore MK, Theodore L. Safe Drinking Water. In Introduction to Environmental Management. CRC Press. 151-158.

29. Slabicki K. Seasonal Variations on the Brandywine River, Total Organic Carbon Removal and Disinfection Byproduct Presence in the City of Wilmington's Drinking Water (Doctoral dissertation, University of Delaware).

30. Nofal A, AlFayyad I, AlJerian N, Alowais J, AlMarshady M, et al. Knowledge and preparedness of healthcare providers towards bioterrorism. BMC Health Serv Res. 2021; 21: 426. PubMed: https://pubmed.ncbi.nlm.nih.gov/33952253/

31. Cha M. Pandemic and the Threat of BIOTERRORISM. Int J Terrorism National Security. 2021; 6: 45-52.

32. Nepal S, Neupane N, Belbase D, Pandey VP, Mukherji A. Achieving water security in Nepal through unravelling the water-energy-agriculture nexus. Int J Water Resour Develop. 2021; 37: 67-93.

33. Acuña-Alonso C, Fernandes AC, Álvarez X, Valero E, Pacheco FA, et al Water security and watershed management assessed through the modelling of hydrology and ecological integrity: A study in the GaliciaCosta (NW Spain). Sci Total Environ. 2021; 759: 143905.

PubMed: https://pubmed.ncbi.nlm.nih.gov/33340864/

34. Chiquito Gesualdo G, Sone JS, Galvao CD, Martins ES, Montenegro SM, et al. Unveiling water security in Brazil: current challenges and future perspectives. Hydrological Sci J. 2021; 66: 759-768.

35. Zhang C, Li J, Zhou Z, Sun Y. Application of ecosystem service flows model in water security assessment: A case study in Weihe River Basin, China. Ecological Indicators. 2021; 120: 106974.

36. Howey K, Grealy L. Drinking water security: the neglected dimension of Australian water reform. Australasian J Water Resour. 2021.

37. Ranjan P, Pandey PK, Pandey V, Lepcha PT. Development of seepage spring for rural water security. InIOP Conference Series. Materials Sci Eng. 2021; 1070: 012047.

38. Ahmad F, Ahmad S, Zaindin M, Adhami AY. A Robust Neutrosophic Modeling and Optimization Approach for Integrated Energy-FoodWater Security Nexus Management under Uncertainty. Water. 2021; 13: 121.

39. Wang RY, Dai L. Hong Kong's water security: a governance perspective. Int J Water Resour Develop. 2021; 37: 48-66.

40. Chorus I, Welker M. Toxic cyanobacteria in water: a guide to their public health consequences, monitoring and management. Taylor \& Francis; 2021

41. Proshad R, Zhang D, Idris AM, Islam MS, Kormoker $T$, et al. Comprehensive evaluation of chemical properties and toxic metals in the surface water of Louhajang River, Bangladesh. Environ Sci Pollut Res. 2021.

PubMed: https://pubmed.ncbi.nlm.nih.gov/33932212/

42. Hashmi SS, Shah M, Muhammad W, Ahmad A, Ullah MA, et al. Potentials of Phyto-Fabricated nanoparticles as ecofriendly agents for Photocatalytic degradation of toxic dyes and waste water treatment risk assessment and probable mechanism. J Indian Chem Soc. 2021; 98: 100019.

43. Archundia D, Prado-Pano B, González-Méndez B, Loredo-Portales R, Molina-Freaner $F$. Water resources affected by potentially toxic elements in an area under current and historical mining in northwestern Mexico. Environ Monit Assess. 2021; 193: 1-20. PubMed: https://pubmed.ncbi.nlm.nih.gov/33782791/ 
44. Sikakwe GU, Ilaumo BU. Geochemical characteristics and evaluation of the potentially toxic metals in surface and groundwater in AkamkpaBiase, southeastern Nigeria. Arabian J Geosci. 2021; 14: 1-22.

45. Lindholm T, Eriksson JE, Meriluoto JA. Toxic cyanobacteria and water quality problems-Examples from a eutrophic lake on Åland, South West Finland. Water Res. 1989; 23: 481-486.

46. He X, Liu YL, Conklin A, Westrick J, Weavers LK, et al. Toxic cyanobacteria and drinking water: Impacts, detection, and treatment. Harmful algae. 2016; 54: 174-193.

PubMed: https://pubmed.ncbi.nlm.nih.gov/28073475/

47. Sivonen K, Jones G. Cyanobacterial toxins. Toxic cyanobacteria in water: a guide to their public health consequences. Monit Manage. 1999; 1: 43-112.

48. Carmichael W. A world overview-One-hundred-twenty-seven years of research on toxic cyanobacteria-Where do we go from here? Adv Exp Med Biol. 2008: 105-25.

PubMed: https://pubmed.ncbi.nlm.nih.gov/18461766/

49. Chorus I, Welker M. Toxic cyanobacteria in water: a guide to their public health consequences, monitoring and management. Taylor \& Francis; 2021

50. Kruk C, Martínez A, de la Escalera GM, Trinchin R, Manta G, et al. Rapid freshwater discharge on the coastal ocean as a mean of long distance spreading of an unprecedented toxic cyanobacteria bloom. Sci Total Environ. 2021; 754: 142362.

51. Welker M, Chorus I, Schaeffer BA, Urquhart E. Planning monitoring programmes for cyanobacteria and cyanotoxins. In: Toxic Cyanobacteria in Water. CRC Press. 2021; 641-668.

52. Weisbrod B. Dynamics of toxic cyanobacteria in lakes and artificial water reservoirs (Doctoral dissertation).

53. Kang $A$, Ren L, Hua $C$, Song $H$, Dong $M$, et al. Environmental management strategy in response to COVID-19 in China: Based on text mining of government open information. Sci Total Environ. 2021; 769: 145-158.

PubMed: https://pubmed.ncbi.nlm.nih.gov/33485207/

54. Guo H, Huang JJ, Chen B, Guo X, Singh VP. A machine learning-based strategy for estimating non-optically active water quality parameters using Sentinel-2 imagery. Int J Remote Sensing. 2021; 42: 1841-1866.

55. Shen D. Water Quality Management. In Water Resources Management of the People's Republic of China. Springer, Cham. 2021; 199-220.

56. Xiong Y, Ran Y, Zhao S, Zhao H, Tian Q. Remotely assessing and monitoring coastal and inland water quality in China: Progress, challenges and outlook. Criti Rev Environ Sci Technol. 2020; 50: 1266-1302.

57. Zhu H, Shanks BH, Heindel TJ. Enhancing CO- water mass transfer by functionalized MCM41 nanoparticles. Industrial Eng Chem Res. 2008; 47: 7881-7887.
58. Powers SE, Abriola LM, Dunkin JS, Weber Jr WJ. Phenomenological models for transient NAPL-water mass-transfer processes. J Contamin Hydrol. 1994; 16: 1-33.

59. Toombes L, Chanson H. Air-water mass transfer on a stepped waterway. J Environ Eng. 2005; 131: 1377-1386.

60. Farajzadeh R, Zitha PL, Bruining J. Enhanced mass transfer of $\mathrm{CO} 2$ into water: experiment and modeling. Industrial Eng Chem Res. 2009; 48: 6423-6431.

61. De Smedt F, Wierenga PJ. Mass transfer in porous media with immobile water. J Hydrol. 1979; 41: 59-67.

62. Steinberger N, Hondzo M. Diffusional mass transfer at sediment-water interface. J Environ Eng. 1999; 125: 192-200.

63. Wunderlich WO. Heat and mass transfer between a water surface and the atmosphere. Tennessee Valley Authority, Office of Natural Resources and Economic Development, Division of Air and Water Resources, Water Systems Development Branch. 1972.

64. Cohen Y, Mackay D, Shiu WY. Mass transfer rates between oil slicks and water. Can J Chem Eng. 1980; 58: 569-575.

65. Siegrist H, Gujer W. Mass transfer mechanisms in a heterotrophic biofilm. Water Res. 1985; 19: 1369-1378.

PubMed: https://www.ncbi.nlm.nih.gov/pmc/articles/PMC3318122/

66. Yue J, Luo L, Gonthier Y, Chen G, Yuan Q. An experimental study of air-water Taylor flow and mass transfer inside square microchannels. Chem Eng Sci. 2009 15; 64: 3697-3708.

67. Boom RM, Van den Boomgaard T, Smolders CA. Mass transfer and thermodynamics during immersion precipitation for a two-polymer system: evaluation with the system PES-PVP-NMP-water. J Membrane Sci. 1994; 90: 231-249.

68. Jamnongwong M, Loubiere K, Dietrich N, Hébrard G. Experimental study of oxygen diffusion coefficients in clean water containing salt, glucose or surfactant: consequences on the liquid-side mass transfer coefficients. Chem Eng J. 2010; 165: 758-768.

69. Heertjes PM, Holve WA, Talsma H. Mass transfer between isobutanol and water in a spray-column. Chem Eng Sci. 1954; 3: 122-142.

70. Ponche JL, George C, Mirabel P. Mass transfer at the air/water interface: Mass accommodation coefficients of $\mathrm{SO}_{2}$, HNO 3, NO 2 and NH 3. J Atmospheric Chem. 1993; 16: 1-21.

71. Hong $\mathrm{Y}$, Soulignac $\mathrm{F}$, Roguet A, Li C, Lemaire BJ, et al. Impact of Escherichia coli from stormwater drainage on recreational water quality: an integrated monitoring and modelling of urban catchment, pipes and lake. Environ Sci Pollut Res. 2021; 28: 2245-2259. PubMed: https://pubmed.ncbi.nlm.nih.gov/32876821/ 